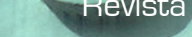

.

LA LARGA AGONÍA DEL PREMIO LUIS CABALLERO

Artículo de Reflexión
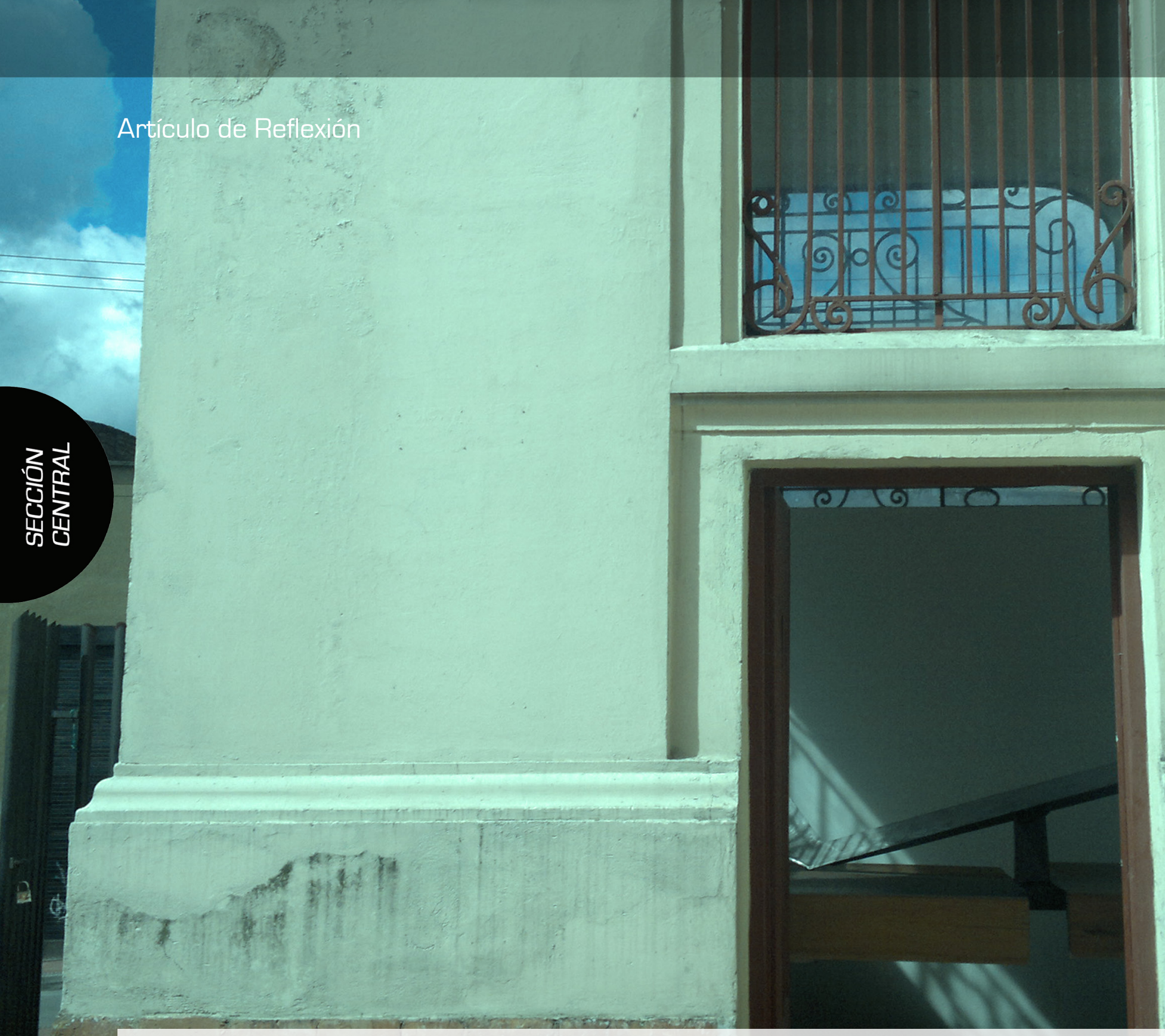

\section{Jorge Peñuela}

jepenuela@yahoo.es

Candidato a Doctor en Filosofía de la Universidad Javeriana. Es profesor de la Universidad Distrital Francisco José de Caldas. 
Mesa Franca. Instalación Consuelo Gómez, VII premio Luis Caballero

[fragmento] 2013. Fotografía: Jorge Peñuela. 2013

PEÑUELA J, [2014] La larga agonía del premio Luis Caballero, Calle14, 9 [14] página 72-91

\title{
LA LARGA AGONÍA DEL PREMIO LUIS CABALLERO
}

\begin{abstract}
RESUMEN
Con base en el concepto de parresía [decir veraz] investigado por Michel Foucault, introduzco el neologismo parresiéstica con el propósito de espaciar en escrituras los gestos artísticos contemporáneos, especialmente los ocurridos con ocasión de la convocatoria nacional del VII Premio Luis Caballero, realizada en 2013 en Bogotá. Al hacer un diagnóstico del campo del arte contemporáneo en Colombia se revela que el fantasma del escepticismo asedia a los artistas, la angustia amenaza a los académicos y la incuria confunde a los espectadores. Después de llevar a cabo un análisis comparativo de los conceptos emitidos por los jurados en los procesos de nominación de artistas y selección del ganador, expongo la necesidad de modelar unos criterios que ayuden a salir de ese estado de cosas y contribuyan al fortalecimiento de las prácticas artísticas contemporáneas en Colombia.
\end{abstract}

\section{PALABRAS CLAVES}

Arte contemporáneo, parresía, escritura, resignificación, gesto, signo, libertad.

\section{THE LONG AGONY OF LUIS CABALLERO AWARD}

\begin{abstract}
Taking as basis the term outspokenness, term coined by Michel

Foucalt wich means: saying something forthrightly. I coin the term outspokenly, with the purpose of giving some space, in the field of writing, to the contemporary artistic gestures, seen at Luis Caballero award at its seventh version in 2013 in the city of Bogota. After carrying out a contemporary art diagnose in Colombia, it was found that artists are besieged by skepticism, anguish threatens literate people, and insouciance disconcerts spectators. In addition the concepts emitted by the jury in the processes of artists' nomination and winner selection were comparatively analyzed, and some ideas are presented in order to establish some criteria which may contribute to enhance the Colombian artistic contemporary practice.
\end{abstract}

\section{KEY WORDS}

Contemporary art, outspokenness, writing, redefinition, gesture, sign, and liberty.

\section{LA LONGUE AGONIE DU PRIX LUIS CABALLERO}

\section{RÉSUMÉ}

Basé sur le concept de la parrêsia [dire la vérité] étudié par Michel Foucault, nous introduisons le néologisme parresiéstica dans le but d'espacer dans les écritures les gestes artistiques contemporains, en particulier ceux produits à l'occasion de la convocation nationale du Vlle Prix Luis Caballero, qui s'est tenue en 2013 à Bogota. Lorsque l'on effectue un diagnostic du champ de l'art contemporain en Colombie, il se révèle que le spectre du scepticisme assaillait les artistes, l'angoisse menace les académiques et la négligence confond les téléspectateurs. 
Après avoir effectué une analyse comparative des concepts exprimés par les jurés dans les processus de nomination d'artistes et sélection du gagnant, je discute de la nécessité de modéliser certains critères pour aider à sortir de cet état de choses et contribuer à renforcer les pratiques artistiques contemporaines en Colombie.

\section{MOTS CLÉS}

Art contemporain, parrêsia, écriture, redéfinition, geste, signe, liberté.

\section{A LONGA AGONIA DO PRÊMIO LUIS CABALLERO}

\section{RESUMO}

Baseado no conceito de parresia [ou seja, veraz] investigado por Michel Foucault, apresentou o neologismo parresiéstica com a finalidade de espaçamento nas escrituras, os gestos artísticos contemporâneos, especialmente os ocorridos por motivo da convocatória nacional do VII Prêmio Luis Caballero, realizada em 2013 em Bogotá. Ao fazer um diagnóstico do campo da arte contemporânea em Colômbia, revela-se que o fantasma do escepticismo assediam aos artistas, a angústia ameaça aos acadêmicos e negligência confunde aos espectadores. Após a realização de um análise comparativo dos conceitos expressos pelos júris nos processos de nomeação de artistas e selecção do vencedor, discuto a necessidade de modelar uns critérios que ajudem a sair deste estado de coisas e contribuiam para reforçar das práticas de arte contemporânea na Colômbia.

\section{PALAVRAS-CHAVE}

A arte contemporânea, parresia, a escritura, a redefinição, o gesto, signo, liberdade.

\section{LUIS CABALLEROTA IMASAPI PREMIOSKA}

\section{SUGLLAPI}

Ima niriagta parresia [Sutipa kagta] Michel Foucault, maskag neologismota chagpichispa chasallatata kilkasakapi. Contemporaniopi suma kawachiri, allillapi karirka cumbiduska Atun llagta. Kanchis premiaska Luis Caballeropa iskai waranga chunga kimsa watapi Bogota llagatapi allilla kawaspa contemporaniopi suma kawari Colombia llagtapi sumaiachigkuna mana tiagkunasina, chasa kawag kunata pandachiri. Allila Sugta Sugta.

Kawaspa iachagkuna willaska iachangapa, pitami chaia premianga chiwan chasapi allilla iachangapa contemporaniopi Colombia llagtapi.

\section{IMA SUTI RIMAI SIMI}

Contemporaniopi, suma kawari, rurag Chasallata kilkai ima niriagta, kawari, rigcha, maimapas. 


\section{Se espacia una parresiéstica contemporánea}

La multiplicidad es cínica y creativa. Los cuerpos múltiples son cuerpos creativamente cínicos ${ }^{1}$. Cuerpos múltiples son aquellos que se hacen visibles en quehaceres realizados al margen del sentido común, e intuibles y comprensibles en sus respectivos cuidados escriturales. Los cuerpos múltiples son la emergencia de un habla veraz que redistribuye permanentemente las porciones de cielo y tierra. Se trata de un habla que una y otra vez exige cambiar de tallador con el propósito de que el poeta remodele los signos que capturan la existencia de un pueblo creativo. Una vez transformados, el artista y el poeta redistribuyen gestos y signos al azar². Entre la tierra y el cielo, ser cuerpo múltiple es abrirse a una ilustración escritural de la verdad del sentido de ser actual, la cual acontece con el gesto del poeta revolucionario. El poeta anuncia la inminencia de un nuevo reparto del bien y el mal. Un reparto de lo sensible, corrobora Jacques Rancière [2009]. El progreso o el mejoramiento de los hombres, se constata a través de los registros históricos que hablan de estas rupturas, de estas discontinuidades en el ser-cuerpos-otros-dispersos. Los cuerpos múltiples son aquella acción que permite a la humanidad realizar un tránsito permanente en doble vía: del epos matérico al logos inmanente, y viceversa.

Foucault despeja la experiencia que tiene la contemporaneidad de su existencia. Se trata de reactualizar el ajuste primigenio, mediante la

1. "[... el el cínico se reconoce a sí mismo y en cierto modo está solo consigo para reconocerse en la prueba que hace de la vida cínica, de la vida cínica en su verdad, vida no disimulada, vida sin dependencia, vida que rehace, deshace la partición del bien y el mal [Foucault, 2010: 311].

2. Kant considera que el acontecimiento de la llustración trae la oportunidad de hacer una redistribución de relaciones entre los seres humanos "[...] lo que la Aufklärung deberá hacer, lo que está haciendo, es justamente redistribuir las relaciones entre gobierno de sí y gobierno de los otros. Según Kant, ¿de qué manera se está produciendo esa redistribución del gobierno de sí y el gobierno de los otros? [Foucault, 2009b: 49]. creación de un espacio en el cual se manifiesta una parresiéstica adecuada al sentir y pensar de la contemporaneidad. Foucault arriesga algunos anacronismos de los cuales se percata. Uno de ellos es el término militantismo, el cual es aplicado a las sectas filosóficas del periodo helenístico y romano. El militantismo es un término que caracteriza los movimientos sociales durante el siglo XIX y las vanguardias artísticas del siglo XX. Justifica su uso porque el periodo que revisa de la Antigüedad tiene las mismas motivaciones que tuvo el siglo XIX para incentivar su activismo político. La descripción realizada de este militantismo puede extenderse al militantismo de las vanguardias artísticas del siglo $X X^{3}$.

3. "[...] Por una parte, sé lo que puede o podría haber de exagerado en la atribución al cinismo de la invención de la militancia filosófica. Ante todo, porque parece un hecho cierto que arraigó su propia práctica en una tradición que le era preexistente. A continuación, y sobre todo, porque cierta militancia existió en grados diversos y bajo formas diferentes en los más numerosos de los movimientos filosóficos de la Antigüedad: escuela, enseñanza general. La militancia cínica forma parte de todo un conjunto de prácticas de proselitismo. Pero lo que constituye su singularidad y la distingue de todas las demás es que se desenvuelve no en un circuito cerrado sino en medio abierto, y no exige una educación, una paidea. Esta militancia cínica utilizará medios violentos, drásticos para sacudir a la gente. Y su singularidad radica, por último, en que pretende acometer únicamente contra las convenciones, las leyes, las instituciones. Es una militancia que aspira a cambiar el mundo. Pero cuando se habla de la militancia cínica no hay que olvidar el conjunto del que forma parte, no hay que olvidar que encontramos en sus cercanías formas de proselitismo filosófico. Tampoco debe olvidarse que los estoicos practican con frecuencia una forma de actividad, de propaganda, que se le parece mucho. Por lo tanto: resituar el cinismo en toda esta familia; pero reconocer en él, no obstante, una forma de militantismo abierto, agresivo, un militantismo en el mundo y contra el mundo. Lo que da su importancia histórica a esta actividad cínica es también la serie en la cual se inserta: activismo del cristianismo que es a la vez combate espiritual, pero combate por el mundo; otros movimientos que acompañaron al cristianismo: órdenes mendicantes, predicación, movimientos que precedieron y sucedieron a la Reforma. En todos ellos se constata el principio de una militancia abierta. Militancia revolucionaria del [siglo] XIX. La verdadera vida como una vida otra, como una vida de combate, por un mundo transformado" [Foucault, 2010: 316]. 
Foucault, sostiene que las primeras vanguardias artísticas del siglo XX, piensan el mismo asunto de las sectas filosóficas antiguas. En especial, percibe una afinidad entre estas y los cínicos. Ambas actitudes manifiestan una inquietud por la verdad, por la libertad de expresión en un mundo totalitario. Los ciudadanos son despojados de una esfera pública en la cual realizar la igualdad prometida en cada una de sus libertades. Esta experiencia de libertad franca e igualitaria fue descrita en la antigüedad bajo el concepto de parresía [Foucault, 2010: 46]. Hasta la Edad Media, la parresía concebida como decir veraz se mantiene en juego con otras modalidades de expresión parresiástica [profecía, sabiduría y técnica] ${ }^{4}$. Bajo el régimen de la burguesía, la conjugación de las primeras tres modalidades de veridicción impidió el ejercicio veraz de la política: la suprimió. Por la injerencia del profeta, el sabio y el técnico en la esfera pública, la modernidad dejó de ser un escenario propicio para el ejercicio de la política. En la contemporaneidad, los artistas vuelven a manifestar una inquietud por la verdad veraz, de manera que su expresión no sea limitada por los otros ejercicios de veridicción. Ni profeta, ni sabio, ni técnico. El artista manifiesta una parresiéstica, una voluntad de verdad cuando con coraje decide modelar su sí mismo. Propicia un encuentro consigo mismo y escucha el llamado de lo insondable en la existencia. La transformación del artista mediante el modelamiento de sí mismo es subversiva porque altera el orden común con que las cosas del mundo están dispuestas.

4. "[...] Y con respecto a la modalidad parresiástica, creo justamente que, como tal, ha desaparecido y ya no se la encuentra sino injertada y apoyada en una de las otras tres modalidades. El discurso revolucionario, cuando adopta la forma de una crítica de la sociedad existente, cumple el papel de discurso parresiástico. El discurso filosófico, como análisis, reflexión sobre la finitud humana, y crítica de todo lo que puede, sea en el orden del saber o en el de la moral, desborda los límites de esa finitud, representa en algún aspecto el papel de la parrhesía. En lo concerniente al discurso científico, cuando se despliega - y no puede no hacerlo, en su desarrollo mismo- como critica de los perjuicios, de los saberes existentes, de las instituciones dominantes, de las maneras de hacer actuales, tiene en verdad ese papel parresiástico". [Foucault, 2010: 46].

\section{Los dispositivos curatoriales}

El premio Luis Caballero [LC] podría ser el estímulo artístico más importante en Colombia, porque sin duda alguna en tierra de ciegos el tuerto bien puede ser rey. Sin conceptos oscuros, la visibilidad de la experiencia artística se esfuma. De hecho, durante los últimos lustros ha sido el rey solitario, un rey expuesto al espíritu mercantil de la época. Sin escritura ni discurso, sobrevive asistido por la propaganda del régimen ideológico. Se nota una ausencia de conceptos oscuros que hagan sombra al espectáculo de luces contemporáneo, que le permitan a los destinatarios de las obras de arte, activar, actualizar y procesar las ideas de los artistas. El concepto artístico no es claro y distinto. Los conceptos oscuros acompañan el tránsito del gesto artístico hacia el lenguaje [Agamben, 2009]. El gesto artístico clama por un signo que lo retenga y lo haga real, que lo haga memorable a los hombres y mujeres por venir. Es un secreto a voces que los Salones Nacionales dejaron de ser un referente de pensamiento plástico para transformar nuestra idiosincrasia feudal, caracterizada principalmente por la resistencia violenta y endémica a los cambios que nos exigen otras maneras de ser, sentir y pensar. En medio de esta sensibilidad agraria, se configura aquella que se denomina contemporaneidad en las artes colombianas.

Hoy los Salones Nacionales basculan entre el espectáculo mediático y comercial de ARTBo y las prácticas etnográficas de fin de semana. De la misma manera, después de muchos años de experimentación empírica, los Salones Regionales no logran ubicarse en el imaginario plástico y social de los colombianos. Ni siquiera dentro del campo del arte. Estos espacios significan poco, no han aportado nada al campo. Tampoco a la sociedad ni al Estado. El diagnóstico es el mismo en los dos casos. Por una parte, no hay producción discursiva acorde con la sensibilidad de los artistas contemporáneos y de la sociedad en su conjunto. Por otra parte, la sensibilidad artística común sueña dogmáticamente en el lecho de las artes tradicionales. El LC nos permitirá realizar un diagnóstico del arte contemporáneo en Colombia. 
En el año 2012, con el inicio de la séptima versión del estímulo más importante del arte contemporáneo en Colombia, no solo queda en entredicho el patrimonio moral del artista Luis Caballero. Las arcas fiscales también sufren un claro detrimento patrimonial con las improvisaciones de las cuales el Estado se vale para sostener su incuria: dejó perder el espacio de exhibición que le dio consistencia y credibilidad al premio. En algún momento del pasado reciente, se pensó que el LC tendría cristiana sepultura y que sus deudos podrían realizar el duelo respectivo. No fue así. Al contrario, hoy yace expuesto como cualquier criminal infame para recordarnos que el soberano sigue siendo una burocracia estética ilegítima. llegítima porque representa los intereses de unos pocos que una y otra vez se lucran de los estímulos económicos que el Estado ofrece a las artes dentro de sus políticas culturales. Permanece insepulto, y es pasto de todo tipo de voracidades estéticas, tanto tardomodernas como posmodernas, tanto formalistas como pseudo-comunitaristas. Sorprende que los representantes legales del artista Luis Caballero aún no hayan querellado al Estado por el mal uso que se está haciendo del nombre de uno de los artistas más interesantes de nuestro pasado reciente. Asombra que los bogotanos tengamos que seguir pagando adecuaciones y arrendamientos onerosos - primero en el barrio La Magdalena, luego en la Candelaria- para que allí disfuncione una sede temporal de la fallida Galería. Al primer lugar iba muy poca gente, allí cualquier instalación quedaba mal montada y los artistas salían mal parados ante la crítica. La crisis es tal que la mitad de la sede temporal se destinó a servir de bodegas para Idartes. El espacio de la Candelaria apenas se inauguró en 2014. Allí convalecerán los principales estímulos artísticos de artes plásticas y visuales otorgados por el Distrito Capital.

Durante los meses de septiembre y octubre de 2013, los colombianos vimos la puesta en escena simultánea de los ocho artistas nominados para la séptima versión del LC. El jurado estuvo compuesto, por una parte, por los artistas Carlos Uribe y Mario Opazo; por otra parte, por Rodrigo Moura, un curador de origen brasileño. Las propuestas seleccionadas dentro de los 32 artistas que respondieron a la convocatoria del Idartes son dispersadas en espacios carcomidos por una tradición aurática local que devora permanentemente a sus hijos, que mediante unas lógicas obsoletas sistemáticamente impide pensar sus archivos en libertad, que es incapaz de renovar sus formas de expresión, exposición y circulación de sus discursos, cuando los dispositivos museísticos permiten que se produzcan. Las intervenciones de lugares sacros sin libertad conceptual ni artística, suelen terminar en ejercicios retóricos que no le aportan nada ni a las artes ni a la sociedad. En la contemporaneidad, una intervención para resignificar está asociada a políticas neocoloniales, hace referencia a una exploración militar tipo Irak. Por lo tanto hay que ser cauteloso en su uso, o hacer muchas aclaraciones. Resignificar es un término que se empodera en los discursos posmodernos [Foster, 2001: 84-99].

La retórica intervencionista quedó evidenciada cuando se puso de moda esta práctica en los Salones Nacionales, especialmente en el Salón de 2006 realizado en Bogotá. Ahora, para que los monumentos seleccionados en esta oportunidad por el Idartes ayuden a abrir senderos de sentido que desaletarguen nuestra escéptica sociedad, los artistas deben tener el coraje de retarlos mediante el espaciamiento de gestos personales que convoquen la creación de signos acordes con la actualidad, que sean capaces de abrir los archivos que los abates locales celosamente ocultan tras unos dispositivos discursivos. Sin duda, este coraje es un ejercicio de libertad que requiere una preparación personal. Sin libertad la imaginación se queda sin recursos para asumir las consecuencias que trae consigo la actitud riesgosa del coraje que va en pos de la verdad que cada época necesita modelar. Un artista de trayectoria como todos aquellos que han hecho presencia en el LC, difícilmente puede someterse a los regímenes museísticos conservadores de nuestro país.

Los "diálogos armónicos" que los curadores explícitamente proponen para la VII versión del LC están enmarcados dentro de los ejercicios retóricos que la posmodernidad impone a algunos artistas. Son diálogos sin ninguna potencia emancipadora. Esta práctica textualista y en algunos casos sofística se comprende hoy como "resignificar". Sin esclarecerlo previamente, "resignificar" es un 
término-comodín que usan tirios y troyanos para darle peso o "solidez conceptual" a sus prácticas artísticas. La burocracia estética de nuestro país, al dividir también vence. El LC fue descuartizado y sus miembros expuestos en los museos de la ciudad durante 2013. Sus restos sobreviven esparcidos como escarmiento a lo largo de la ciudad, y el nombre del pintor ilustre y su práctica artística, personal, subjetiva y autobiográfica, puestos al servicio de ideas plásticas neoconservadoras y retardatarias.

\section{El artista contemporáneo opta por el cuidado de sí}

A pesar de su ceguera parcial, el premio Luis Caballero es importante para la ciudad, aun en esta séptima versión que culminó en noviembre de 2013, y esto pese a las improvisaciones espaciales a que dio lugar su salida de la antigua Galería Santa Fe. Se nota cómo el cuestionado Museo de Arte Moderno de Bogotá se constituyó en el espacio más solicitado por los artistas para la puesta en escena de sus ideas, lo cual es un indicador de la crisis que atraviesa el arte contemporáneo en Colombia. Esto se manifiesta principalmente en la ausencia de espacios de exposición acordes con las nuevas ideas de los artistas, y nuestras maneras de ser y sentir nuestra época. No es que el Mambo sea insignificante, "intrascendental" como afirma contradictoriamente Carlos Uribe. Este jurado objetó la propuesta al LC de Germán Arrubla, por haber elegido este espacio para mostrar sus ideas. [No obstante, al mismo tiempo Uribe no duda en "sugerir" a Sergio Giraldo, uno de los nominados para esta versión, que su proyecto debe ser instalado allí, y no en el segundo piso de la Nueva Galería Santa Fe, como fue la propuesta original del artista ${ }^{5}$.

5. Cf. Conceptos de Carlos Uribe, jurado de selección de la séptima versión del premio Luis Caballero. Estos conceptos fueron suministrados por la dirección del Idartes, como respuesta a un Derecho de Petición presentado por este investigador. Ante la crisis en que quedan la Galería Santa Fe y su premio emblemático, se presenta este Derecho de Petición con un propósito: determinar los criterios de selección y evaluación de los artistas nominados para esta versión del premio.
El contencioso plástico va por otro lado. El Mambo representa para muchos artistas colombianos una estética aristocrática contraria al pensamiento artístico contemporáneo que quiere salirse del régimen venal y publicitario, que lucha por emanciparse de un conjunto de galerías de arte que son puestas al servicio de los decoradores de interiores que suplen las necesidades suntuarias de la elite comercial de nuestro país. Los administradores del Mambo, líderes de nuestro campo y reconocidos sin mayores reservas en su momento, fueron rezagados por una contemporaneidad intensa, que intenta instaurar un orden ascético cristiano en el arte colombiano. Tardíamente, la delicadeza de gusto promovida por la modernidad dejó de ser un lugar de encuentro para los artistas colombianos. Por lo tanto, esta estética con la que fuimos socializados, y que tiene como garante a este museo citadino, dejó de ser el referente obligado que fue para los artistas colombianos en el pasado reciente. Los artistas contemporáneos ya no gestionan ni prometen felicidad, el mullido sillón prometido por Matisse a sus fieles seguidores. Realizan un retiro, una vuelta sobre sí mismos para librarse de las retóricas con las cuales se les maniata, con las que se les arrebata la imaginación. Es un retiro que no es una renuncia al mundo, ni mucho menos. Es una preparación para un más acá exigente, conflictivo, individualista, comercial, esclavizante, sin ningún tipo de garantías por fuera de las matrices masificadoras que el Estado de Opinión Común instituye como matriz universal para la constitución de sentido ${ }^{6}$.

Tampoco es un secreto que el artista contemporáneo en Colombia anda con caminadores diseñados por el Estado e impuestos por los curadores de turno para que "sus" artistas aprendan a caminar en la ciudad, a "dialogar" con las comunidades, en las "regiones" que se visitan en época de Salones. ¡Sí! ¡Así de fácil! ¡Como si dialogar fuera la actividad más sencilla y natural del mundo! ¡Como si la complejidad de un diálogo sin filtros ni puertas cerradas fuera un asunto

6. Durante sus últimos cursos en el Collège de France, Michel Foucault hizo una investigación del cuidado de sí [Foucault, 2009, 2009b, 2010]. 
que pudiera resolverse en una convocatoria estética! Este es el caso del Nuevo Luis Caballero. ¿Cómo se le colgó este orangután al denominado "estímulo artístico más importante de Colombia"? ¿Quiénes fueron los gestores que redujeron el arte contemporáneo a la versión de la posmodernidad más banalizada por los artistas? En efecto, a partir de esta versión del LC, los artistas están obligados a "dialogar armónicamente" en espacios determinados por el Estado y en los que el artista sigue siendo un arrimado, un patico feo, un perrito al que se le construye su casita provisional, en el solar o el jardín de algún monumento estatal vacuo o inocuo. Se sabe que estos espacios carecen de sensibilidad por la actualidad y no tienen perspectivas emancipatorias, tampoco sus dirigentes cuentan con la disposición mental necesaria para que el artista logre conquistar las distancias previas que requiere todo diálogo acerca del futuro.

Carlos Uribe se refiere en términos elogiosos - dialogar armónicamente- a la propuesta de Fredy Alzate para el Museo Leopoldo Rother de la Universidad Nacional. El juicio de este curador tiene un tono políticamente correcto, pues, la armonía formal es una característica de esa belleza que nuestras élites echan tanto de menos en el arte contemporáneo. La armonía es aquel estado al que aspira todo lo imperfecto. La armonía, pues, es perfección y se constituye en expresión de belleza7. Sin embargo, es poco lo que se puede esperar de un "diálogo armónico" como el que Uribe le propone a Alzate, como el que exigen e imponen todos los espacios envenenados que les fueron impuestos a los artistas. Con sofistería, a este "diálogo armónico" Uribe lo denomina "resignificar", término con el cual este curador recoge la ideología neoconservadora que apreciamos en los conceptos con que varios artistas fueron sacados del juego plástico nacional para esta versión del LC. "Resignificar": coleccionar figuras retóricas gastadas y sin brillo: el artista como

7. Cf. Baumgarten, A.G.; Winckelmann; Mendelssohn. M.; Hamann, J.G. [1999] Belleza y Verdad. Barcelona: Alba Editorial, S.L. coleccionista de corazones secos ${ }^{8}$.

\section{Exploración personal y servicio social}

Carlos Uribe descalificó varios proyectos por el simple hecho de ser propuestas "personales", "subjetivas" o "biográficas": ¿a qué se debe la desinformación e incuria de este curador? ¿Cómo pretende el Estado que el artista "dialogue" con la ciudad, si este no es capaz de mirarse a sí mismo? Si el artista no logra crear una distancia que le permita modelarse a sí mismo, ¿cómo puede intervenir espacios cargados de significados que son vigilados celosamente por los abates de nuestro medio? Si el artista no tiene el coraje de construir la subjetividad que le permite trasformar lo ya interpretado, si no alcanza a conjurar las fuerzas necesarias para salirse de los regímenes discursivos desérticos con que su imaginación es allanada, ¿cómo puede salir a dar cuenta de lo humano y lo inhumano? Si previamente se le indica que debe horrorizarse de su sí mismo, ¿cómo puede mostrar las subjetividades contemporáneas que en cada esquina o rincón de nuestras ciudades retan nuestros imaginarios carcomidos por el óxido de la tradición? ¿Por qué ignora Uribe que la exploración de un diálogo personal consigo mismo es una preparación para el diálogo complejo, con el cual se construye una ciudad configurada por una multiplicidad de subjetividades? ¿La ausencia de una construcción personal de una subjetividad no frustra la posibilidad de cualquier diálogo? Solo mediante una pedagogía que incentive la importancia de los ejercicios mediante los cuales se puede modelar una subjetividad, se puede aspirar a dirimir las diferencias apabullantes que apreciamos por doquier, diferencias que luchan por silenciarse unas a otras. Sin duda, en Colombia estamos ad portas de entrar en la era de los artistas infames, con el

8. "Son deplorables aquellos que solo leen los escritos de los inmortales Antiguos para descomponerlos y coleccionar figuras retóricas como hace un entomólogo con los corazones secos de los gusanos. Buscan y encuentran las reglas de la elocuencia; se erigen en legisladores de las bellas ciencias, pero han dejado de sentir esas bellezas que tanto nos elogian. Su sentimiento se transforma en una conclusión lógica" [Mendelssohn, 1999: 131-132]. 
pintor Luis Caballero a la cabeza. A partir de esta versión del LC, constituye una infamia pensar una propuesta personal. El régimen comunitarista que nos implementó Carlos Uribe no está lejos de considerar como arte degenerado las propuestas "subjetivas" que realizan los artistas colombianos contemporáneos.

Uribe desconoce que los jurados de la quinta y sexta versión de este premio destacaron a Mario Opazo y a Fabio Melecio Palacios, precisamente porque sus ideas estéticas fueron puestas en tensión por su experiencia de vida, porque con ellas exploraron una problemática muy personal, autobiográfica; porque sus imágenes surgieron de una distancia que les permitió configurar una realidad plástica más allá de la vaguedad de las anteojeras de "lo político" y "lo social" tan en boga en nuestros días. Las problemáticas políticas o sociales planteadas en las propuestas de los dos últimos galardonados del LC son una trivialidad si no se miran desde la experiencia de vida que los artistas se propusieron cuidar, "curar" de la enfermedad que asola al arte contemporáneo en Colombia: la curaduría como institución panóptica al servicio del régimen del mercado de bienes. En nuestra opinión este es el talón de Aquiles de la práctica artística de Clemencia Echeverry. Lo extraño es que Opazo, jurado para esta versión, no hizo notar esta especificidad que determina la sustancia del arte contemporáneo en Colombia, a saber, su alejamiento del victimismo en que tantos artistas se solazan acríticamente.

Afirmamos que en las últimas propuestas ganadoras del LC se presenta un giro contemporáneo del arte en Colombia hacia estas pequeñas historias vividas por los artistas en carne propia y en las cuales el artista se retira para aprender a dialogar consigo mismo, como condición indispensable para comenzar a meditar acerca de la comunidad y sus males, antes de ponerse en la tarea de "resignificar" un mundo dividido entre víctimas y verdugos, antes de dar cátedra sobre "diálogos armónicos de ciudad", todo esto sin previamente haber comprendido los misterios guardados por el habla, sin haber aprendido a usar la palabra ni atrevido a preguntarse acerca de su esquiva naturaleza.
La banalidad de los diálogos con la ciudad que caracteriza al populismo etnográfico de nuestros días se puso de manifiesto tardíamente en este LC. El asunto es tan evidente que Rodrigo Moura afirma que la propuesta de Consuelo Gómez, otra de las artistas nominadas, es "pseudocívica". Este jurado afirma que "a pesar [de] que existe un comentario directo sobre el espacio [plaza de mercado de Las Cruces], no se integra con sus habitantes". Es decir, los productos de Gómez no logran romper su formalismo. Así sean llevados a una plaza de mercado, no logran salir de su mutismo, siguen permaneciendo cerrados para el ciudadano de la calle. Aquí debemos plantear una pregunta obligada: ¿cómo fue nominada esta artista con esta objeción estructural? ¿Cómo fue nominado Sergio Giraldo a quién se le tuvo que "sugerir" un cambio de espacio? El montaje de Consuelo Gómez mostró que mediante este ejercicio, su escultura sí logró conmover a los vecinos del lugar. Por su lado, el montaje de Sergio Giraldo en el Mambo fue de los más débiles y nos hace sospechar que el cambio de lugar echó a perder una buena idea.

\section{Las lógicas invisibles del arte contem- poráneo}

El punto tres [3] del protocolo que siguieron los jurados evalúa la "coherencia entre la propuesta y el espacio específico" propuesto por el artista. Aunque la coherencia no es un criterio para juzgar un trabajo artístico, porque, como lo esclareció Sol Lewitt, las ideas estéticas saltan por encima de estas andaderas lógicas comunes, lo cierto es que varios proyectos fueron descalificados con base en este criterio. Como se sabe, la coherencia es un principio de la lógica matemática, y es necio y trivial intentar aplicarlo en el campo de las artes. Es necio porque aquello que las artes buscan es dar una sorpresa a la lógica que maniata la imaginación. Este golpe de sorpresa busca burlar a los cancerberos del régimen curatorial en Colombia. Artista que no tenga claro este principio de creación está en el lugar equivocado. Precisamente, el régimen etnográfico 
premio

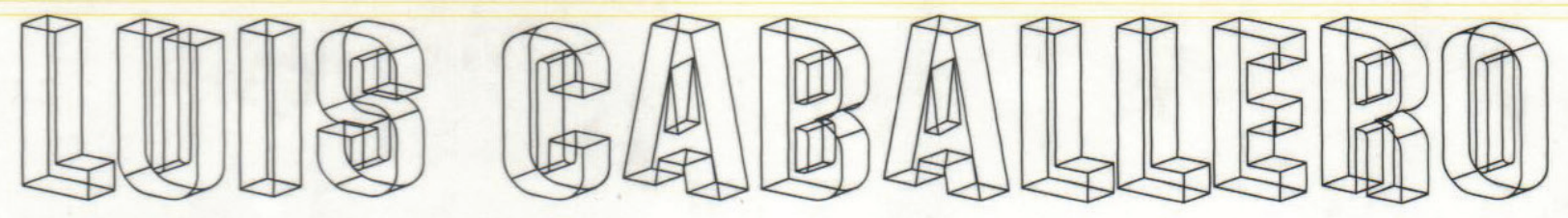
catálogo general

2001

- aIDCT

1 Ej. 1/1 


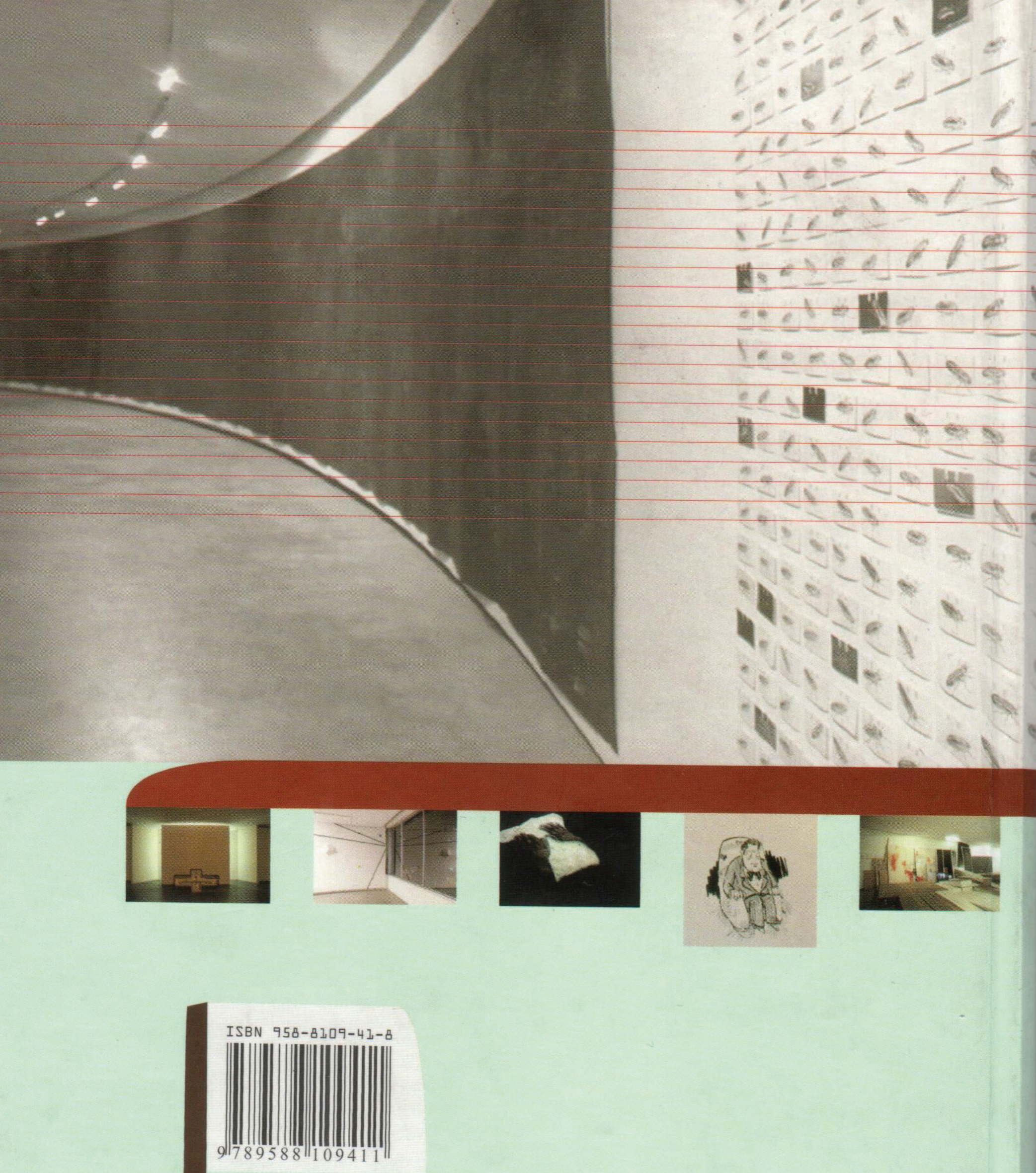


que se tomó el arte contemporáneo realizado en Colombia, convierte las sorpresas en objeto de persecución, exige al artista contemporáneo colocar su pensamiento acorde con las conclusiones lógicas que los intereses del Estado promueven, a saber, que sean seguras y habituales para el entendimiento común, el entendimiento empobrecido de una sociedad enferma de escepticismo. Solo a un espíritu esnobista se le pudo haber ocurrido este exabrupto teórico. Solo un artista sin imaginación se puede sentir cómodo en este régimen. Los artistas no argumentan, no hacen demostraciones, no se dejan someter ni encerrar dentro del lazo férreo de esta lógica instrumental, por esto se constituyen en alternativa emancipatoria para contrarrestar la arrogancia y pedantería que caracteriza tanto al pensamiento científico, al ámbito económico y a algunas filosofías contemporáneas.

El pensamiento artístico rompe con todas las causalidades lógicas y las determinaciones espaciales que defiende Carlos Uribe en su jurisprudencia para el LC. Por esta razón, los "diálogos de ciudad" que este último reclama, azuzado por las indicaciones que recibe del Estado, no pueden convertirse en criterio para el juicio artístico. Sin embargo, Uribe, artista de importante trayectoria dentro del mismo LC, restriega este concepto una y otra vez en la poética de los artistas evaluados, y los descalifica por su "poca" o "insuficiente coherencia". Me centro en los juicios de Uribe, porque Moura y Opazo dan la impresión de haber sido convidados de piedra en este Banquete en que algunos artistas ofrecieron ingenuamente sus vísceras, cuando lo que el Estado esperaba era "conceptos coherentes". En estos dos últimos jurados, el copy and paste cae una y otra vez sobre la cabeza de los artistas, se repite de manera inclemente en la mayoría de los conceptos presentados a la dirección del Idartes. En general, el copy and paste cayó como una guillotina en la cabeza de los artistas descalificados y operó como comodín para producir cada uno de los conceptos exigidos por el protocolo del Idartes. Si a esto se le puede llamar "producir", o si estas notas escuálidas alcanzan para configurar un concepto respetuoso con los/las artistas que respondieron la convocatoria.

Pese a las andaderas comunitaristas promovidas e impuestas desde el Estado al LC, este sigue siendo importante, insistimos, pese a sus gestores, administradores y legitimadores. Son muchos los nombres que nos sirven de indicadores para establecer la relevancia plástica nacional de este estimulo estatal, aun en esta triste ocasión en que la "comunidad" enmascarada mostró unas uñas afiladas diligentemente por los curadores en la piedra ideológica promovida desde el Estado. Atendieron esta convocatoria, Mariana Varela, Humberto Junca, David Lozano, Juan Mejía, Franklin Aguirre, María Elvira Escallón, José Alejandro Restrepo, Andrés Villa, Consuelo Gómez, Manuel Quintero, entre otros. La mayoría de los artistas con presencia nacional. Sin embargo, la selección de los nominados llama la atención del investigador crítico no tanto por quienes fueron nominados sino por quienes quedaron tendidos en el piso comunitarista, tejido sofísticamente entre los jurados designados para este LC y los administradores del Idartes. ¿Cómo puede decir Rodrigo Moura que la trayectoria artística de David Lozano "no es acorde con los requisitos de esta convocatoria"?. Por lo menos, el artista se merecía una explicación, pero Moura no la da. Este juicio arbitrario fue copiado en los cinco aspectos evaluados de la propuesta de Lozano. ¿Cómo puede repetir impúdicamente el mismo jurado por medio del copy and paste, que María Elvira Escallón tampoco tiene la trayectoria necesaria para participar en el LC? Moura estuvo en el lugar equivocado, y ni él, ni el ldartes, ni sus compañeros se dieron cuenta de su ausencia presente. [¡Ay Salón Nacional!]. ¡Los caminos de Dios y de los Curadores en Colombia son inescrutables! ¡Quizá todos estuvieron en otra parte! Uribe, por lo menos, dejó sus rasguños comunitaristas en la mayoría de las propuestas evaluadas. Moura no supo que Escallón ganó con Nuevas Floras la tercera versión del LC, a no ser que considere que su participación en este premio fue un error. Respecto a Escallón, Uribe afirma que la propuesta es una búsqueda personal de la artista y que "equivoca el sentido de la convocatoria al utilizar su investigación como un comodín que se 
puede albergar en cualquier lugar". Suponemos que Uribe conoce el "sentido de la convocatoria", pero no la explicita. Debe conocerlo, pues él mismo participó con Escallón en la tercera versión del premio, precisamente en la versión en que esta artista persuadió al jurado respectivo con sus ideas estéticas.

Moura vuelve a "copiar y pegar" el mismo juicio descalificatorio con respecto a la propuesta de Humberto Junca. Para este jurado la trayectoria del artista tampoco "es acorde con los requisitos de esta convocatoria”. Afirma que la coherencia entre la propuesta y el espacio específico "no es acorde con los requisitos de esta convocatoria", aunque no especifica en ninguno de los dos aspectos que censura cuáles son las fallas: ¿no sabe Moura que Junca ya participó en un LC? ¿También fue un error su participación en la cuarta versión del LC? La afirmación de que Junca no tiene el perfil para el LC, merece una explicación por parte del jurado. Y esta vez la exige el mismo campo artístico. ¿Estarán hablando los jurados del mismo LC que conocemos los/las bogotanas? 0, azuzados por el ldartes, ¿tienen en mente un LC marcado por signos de una comunidad posmoderna invisible, cuyos artistas y amanuenses simulan "resignificar" para no tener que decir nada, para dispensarse del deber de tomar una posición distante? ¿Los jurados quieren enterrar este estímulo que hasta la sexta versión fue orientado por inquietudes de artistas con búsquedas personales, con necesidad de crear una subjetividad que les permitiera tomar la palabra? Este tipo de búsquedas caracteriza al arte contemporáneo y tiene en el artista Luis Caballero a uno de sus principales mentores en Colombia. ¿Cómo puede equivocarse un jurado en un asunto tan delicado? ¿Cómo Moura puede repetir curaduría, esta vez en el Salón Nacional? ¿Cómo puede el Idartes hacer caso omiso de esta situación y trasladar la responsabilidad de estas decisiones a los jurados para quedar limpio de la sangre derramada de los artistas? Bertha Quintero responde que no es responsabilidad del Idartes la incompetencia del jurado? .

9. Subdirectora de las Artes del Idartes, quien respondió un Derecho de Petición de quien esto escribe.
Muchos de los pre-juicios emitidos por el jurado de selección para nominar los aspirantes al LC 2013 obligan al ldartes a cambiar el jurado para la premiación. No hubo cambios a este respecto, pero sí un artista premiado. Inicialmente, en el momento de responder el Derecho de Petición, Bertha Quintero aún no sabía si habría presupuesto para ello. Sobre el primer punto, juicios previos con respecto a algunos artistas y propuestas terminaron por sesgar desde ese momento un juicio imparcial final. Por ejemplo, con respecto a José Alejandro Restrepo, Carlos Uribe, en el punto correspondiente al Aporte al campo artístico, responde: "sin mayores comentarios". Aunque el punto evalúa algo que solo un agorero de arrabal puede pronosticar y por ello mismo es una trivialidad, este "sin mayores comentarios" nos indica a priori que el aporte de este proyecto al arte colombiano es evidente, sin siquiera el artista haberlo puesto en escena. Para Uribe, el proyecto de Restrepo brilla como una idea platónica. Lo mismo puede decirse de las objeciones de Rodrigo Moura a la propuesta de Consuelo Gómez y de Sergio Giraldo. Respecto a este último artista, el jurado pregunta acerca de "lo que esta nueva oportunidad añade a estos proyectos ya realizados" [Moura se refiere a los proyectos previos de Giraldo con discapacitados que deben hacer uso de sillas de ruedas en espacios interrumpidos con escaleras]. Mario Opazo fue más práctico. Se valió de los comodines que censura Uribe y al punto cuatro [4] del protocolo de evaluación, Aporte de la propuesta al campo artístico, contestó lacónicamente: "siempre puede haber aportes". En todos los casos copió y pegó la misma fórmula. Por su parte, Moura fue más prudente: en la mayoría de los casos no evaluó este aspecto. Finalmente, a último momento, un día antes de emitirse el fallo del jurado, Moura declinó la invitación a hacer parte del jurado. ¿El Idartes habrá tomado nota respecto a la banalidad de aquello sobre lo que indaga su protocolo? Se habrá preguntado, más allá de la Respuesta Oficial para la galería, ¿cuáles fueron los motivos reales que sacaron a Moura del LC? Lo dudamos. Si leyeron los conceptos que les fueron presentados, no los entendieron. Respeto al retiro de Moura, algo no cuadra, pero de eso nadie habla. Es de mal gusto hacerlo. 
Es difícil saber cómo se sorteará esta tensión entre las diferentes estéticas o gustos de los jurados, pues Uribe descalificó a María Elvira Escallón y a Franklin Aguirre por considerar que en sus propuestas se pone en juego un comodín personal que aparece en todos los proyectos de estos artistas. ¿No es este el mismo caso de Sergio Giraldo, y Uribe prefirió aquí cerrar los ojos ante esta evidencia? Aunque el caso de Giraldo es algo diferente, al parecer mantiene un doble juego muy provechoso. En efecto, en su producción reciente podemos apreciar una propuesta pictórica bastante sugestiva, aunque con guiños seductores al mercado, y otra con guiños humanitarios al Estado y los curadores que promueven puestas en escena comunitaristas. Pero parece que este doble juego no solo es una práctica de Giraldo. Otros nominados al premio Luis Caballero 2013 mantienen esta mirada coqueta a los dos bandos en conflicto que configuran la contemporaneidad: mercado de bienes suntuarios y emancipación poética. Poética: producción de uno mismo que coincide con las necesidades silenciosas de una época.

Por otro lado, está el juicio de Moura respecto a Mariana Varela, de quien dice: "su participación en este premio es un justo homenaje a una artista que lleva trabajando incansablemente desde los años 70's". Moura se equivoca de nuevo y demerita la propuesta de Varela con unas lisonjas que no vienen al caso. ¡Claro que Varela es una gran artista! ¡También Restrepo, Lozano, Gómez y Junca! Pero este no es el caso, esto no es lo que se está juzgando. Esta idea no puede convertirse en criterio final de la evaluación de esta versión. El LC todavía no ha incursionado en esta fase de homenajes que anuncia y desea Moura. Si así fuera, Clemencia Echeverry habría ganado la sexta versión del LC, pues, dentro de su amplia trayectoria profesional, la última fue su segunda participación en el LC. En esta no ganó porque su trabajo no fuera meritorio, pues lo es, y lo dijimos en su momento. El asunto fue que la propuesta de Fabio Melecio les pareció a los jurados más personal, más sincera y sentida, más veraz y acorde al sentir silencioso de nuestra época y, por ello mismo, más fresca y sin reverencias conceptuales ni técnicas. Lo central de su puesta en escena consiste en que se presenta desprovista de los caminadores automáticos sofisticados con que el mercado de bienes tecnológicos incapacita a las mentes más brillantes de nuestra época. Por estas razones, las propuestas de Varela, Restrepo, y los otros seis artistas nominados, deberán juzgarse al margen del aura que proyecta cada uno de sus nombres. Como el aura suele deslumbrar a la crítica, afecta a algunos artistas; por supuesto, la evaluación final debió ser realizada por otros jurados ya que quienes la hicieron se habían auto-inhabilitado. No obstante, sería interesante que a futuro el LC rindiera homenaje a uno de los muchos artistas colombianos de amplia trayectoria nacional, a uno de esos que han creado pacientemente una obra personal de mucha ascendencia, no tanto en el mercado de bienes materiales como en la juventud de nuestro país, y fuera invitado a participar sin pasar por los filtros molestos aunque necesarios de los jurados-curadores. Pienso en Dioscórides Pérez, Umberto Giangrandi, Miguel Ángel Rojas, pero hay muchos y muchas otras que pueden ser objeto de homenaje al margen de la competencia central por el Luis Caballero.

Como colofón, no podemos dejar de mencionar que el jurado para esta versión del LC no cumplió con lo previsto en la Cartilla del concurso, punto nueve [9]. Del jurado. "[...] emitirán individualmente un concepto escrito de cada una de ellas [las propuestas] y se reunirán en jornada de deliberación, con el fin de seleccionar las propuestas ganadoras, previa suscripción de un acta en donde se dejará constancia de los criterios aplicados para efectuar la recomendación de la selección" [negrillas nuestras). Debemos reconocer que la labor de los jurados no es una tarea fácil cuando se trata de evaluar artistas que están en el mejor momento de sus carreras y cuentan con un amplio reconocimiento nacional en muchos casos, e internacional en otros. No obstante, si se acepta tal responsabilidad debe asumírsela plenamente y no a medias, mucho menos valiéndose del ignominioso copy and paste para salir del paso. Por supuesto, son bienvenidos los nuevos nombres que comienzan a aparecer al lado de artistas de carreras ya consolidadas. Aquello que hemos expuesto en este diagnóstico que ahora termina, consiste en que los criterios del juicio en asuntos tan delicados para orientar 
el arte contemporáneo en Colombia y en el cual el Estado invierte sumas importantes, deben ser más claros, mejor pensados y aplicados por los jurados con la mayor transparencia. ¡Aquí sí debe haber coherencia en el juicio! Por supuesto, no creemos que haya mala fe en los jurados, solo que no manifiestan claridad conceptual para dirigir sus juicios. Tampoco decimos que esta sea la primera vez que aparecen inconsistencias en el LC. Se trata solo de que el ldartes no tiene archivos sino de esta versión que apenas comienza. No puede concluir nada porque no tiene historia. La memoria no es algo que le preocupe al Estado, tampoco al artista, mucho menos al ciudadano de a pie. ¿Dónde está el archivo de las seis versiones pasadas del LC? No existe.

Pues bien, finalmente, el jurado no hizo bien su tarea, los conceptos individuales no dicen nada acerca de las ideas de los artistas, y el acta en la que debían informar al Estado y a la ciudadanía en general acerca de los criterios aplicados en sus juicios, no fue redactada. El Idartes tampoco exigió cumplir con este requisito que fue establecido de manera expresa en la Cartilla. 0 hizo caso omiso o no leyó, o si leyó no comprendió lo que escribió, lo cual al parecer es un síndrome nacional.

\section{Conclusión}

Con el estudio de los conceptos emitidos por los jurados de la VII versión del Premio Luis Caballero se han formulado preguntas que nos urgen a realizar una investigación acerca de los procedimientos y criterios que operan en cada una de las convocatorias que realiza el Estado para el estímulo de las artes. Mostramos la necesidad de pensar un corpus conceptual adecuado al sentir de nuestra época, acorde con las maneras de pensar que se están configurando y a las libertades que se están abriendo paso por diferentes y diversos medios. La idea de una parresiéstica puede contribuir a esta necesidad del arte contemporáneo en Colombia. Este problema lo abordo en mi tesis doctoral Conquista de una parresiéstica contemporánea. El decir franco y veraz que Foucault recoge de la antigüedad clásica se adecua a nuestra contemporaneidad. Se trata de mostrar una actitud en que aquello que decimos públicamente debe estar en armonía con nuestras prácticas de existencia más personales. Esto desde el punto de vista conceptual. Otro asunto es la praxis del juicio estético.

Pese al gran esfuerzo realizado por Cristina Lleras y al profesionalismo del equipo de producción de la Sede Temporal de la Galería Santa Fe para el montaje y exhibición del VII premio Luis Caballero, la herida del estímulo estatal más importante con que cuenta el arte contemporáneo en Colombia, sigue abierta, su Idea no aparece por ningún lado. Los ejercicios presentados por los artistas no evidencian ninguna urgencia de ser que sea fundamental para comprender la actualidad. En este sentido, el estímulo estatal y la imaginación de los artistas nominados quedan hibernando. Ahora que el mercado condiciona los imaginarios artísticos y nadie se pregunta por las ideas que reivindican las artes, cabe preguntar: además de promover el interés general por las artes mediante el sostenimiento de este estímulo, ¿el Estado se propone algo más? ¿Solo se trata de estimular mecánicamente a los artistas? ¿El premio Luis Caballero consiste en una experimentación, en una improvisación cualificada, en una intervención comunitarista, en un dispositivo comercial más de exposición?

Pese a la estabilidad momentánea, es relevante peguntar hacia dónde se dirige la ldea de arte detrás del premio Luis Caballero. ¿Hay alguna Idea que le dé sentido a este estímulo, o la ciudadanía se tendrá que conformar solo con la eficiencia administrativa que momentáneamente lo rescató de una muerte inminente? ¿Los jurados nominadores orientan esta urgencia de unidad en variedad? 0 al contrario, ¿todos los caminos del arte deben conducir hacia las boutiques de ArtBo? Muchos creen que no. Consideran de vital importancia tomar distancia respecto a la apertura económica impuesta desde el Ministerio de Cultura desde el 2013 en la puesta en mercado del Salón [Inter]nacional de Artistas. Son muchos los artistas que han denunciado este complot del Estado neoliberal.

La Idea del premio Luis Caballero no es una entidad a priori, es el resultado del encuentro en acto de múltiples singularidades artísticas, críticas, 
históricas y pedagógicas, puestas en conflicto por las lógicas administrativas implementadas desde el Estado. Cristina Lleras recopiló y visibilizó todos estos testimonios que a nadie importan en la actualidad. Este es un buen comienzo para decantar la Idea de arte detrás del premio Luis Caballero. No obstante, concluida la séptima versión en 2013, esta idea no logra emerger, el testimonio empírico visibilizado no logra mostrar ese algo más que todos esperamos de las artes, y el cual justifica la esperanza y la inversión de la Alcaldía Mayor de Bogotá en el talento nacional. El premio no puede reducirse al favorecimiento de nuestros correligionarios, mucho menos a premiar la madurez comercial de ningún artista. La ciudadanía espera más, espera una meditación que cambie nuestras maneras de comprender y juzgar al otro diferente. Los jurados designados para evaluar la producción artística nacional, deben proporcionar esta reflexión. Aunque la ciudadanía que sigue de cerca las vicisitudes del arte contemporáneo, no es tan ignorante como algunos artistas modernos aún creen, es deber de los jurados esclarecer el horizonte del arte que juzgan.

Si se escribe acerca de los artistas nominados, si se habla del artista ganador de la séptima versión del premio Luis Caballero, si se elogia la gestión de Cristina Lleras y se comenta el profesionalismo del equipo de producción de la Galería Santa Fe, justo es que se estudie el aporte final de los jurados designados para orientar la deriva del arte pensando en Bogotá y financiado con recursos fiscales. Extrañamente, al concepto emitido por los jurados no se le presta atención. Pese a que esta reflexión sobre lo visto y evaluado debe ayudar a comprender mejor y ampliar la mirada al arte colombiano, ¿por qué a nadie le interesa? ¿Qué extraña tradición oral en el campo del arte colombiano hace que se desprecien este tipo de escritos? La respuesta es lapidaria: jno dicen nada!

El concepto final del jurado de la séptima versión del LC, el cual debiera contribuir a fortalecer la experiencia de los participantes y de la ciudadanía en general, no aporta nada a la discusión contemporánea de las artes. A pesar de que el jurado estuvo conformado por reconocidos agentes del campo del arte y de que estuvieron al tanto de aquello que se estaba produciendo, su contribución al premio es nula. Paradójicamente, quizá esta carencia se deba a sus diversas responsabilidades artísticas: un salón aquí, una curaduría allá, una exposición allí, un viaje acullá, las clases a sutanito o a menganito, en fin... Los artistas cercanos al régimen atienden mil compromisos, entre ellos los mandados estatales. En esta oportunidad, los jurados no proponen ningún criterio que modifique o enriquezca nuestra mirada. No hacen ninguna consideración respecto a las condiciones que afectan la libertad de la expresión y circulación artística por fuera y dentro de los protocolos estatales. Y lo más grave aún, no se evidencia la aplicación de ningún criterio no-empírico para ilustrar o justificar su decisión. Se limitan a repetir aquello que cabalísticamente escribe el mismo artista en su declaración de principios y medios. Atropellada y apresuradamente, el jurado informa al Estado de la siguiente manera:

"Restrepo utiliza la estructura de los Ejercicios espirituales de san Ignacio de Loyola para indagar en lenguajes híbridos, a medio camino entre el teatro y el performance. El artista utiliza la estructura de los Ejercicios en diálogo con las metodologías propias de la actuación para revisar documentos de la historia reciente. La obra refleja un espíritu de experimentación colectiva a la que se adhieren relaciones limítrofes entre lo performativo, lo teatral, lo instalativo y otras disciplinas. A su vez, el jurado reconoce en su obra la potencia y aspiración conceptual amplia y universal. Su obra se constituye en una reescritura de su archivo de obra en relación con lo colectivo. Es la constatación de la madurez de un artista que ha insistido en investigar en torno al estado de lo político, de la religión y las creencias con el trasfondo del conflicto colombiano, otorgándole un lugar y una responsabilidad al poder de la imagen".

Punto aparte. No se dice nada. Los jurados encriptan mucho más la cábala artística. Se introduce la tangente como una figura retórica transgresora. No se explica qué busca el artista en su indagación y exploración de los lenguajes híbridos, no se muestra en qué consiste la metodología utilizada por el artista, ni su utilidad. Tampoco se estudia cómo la estructura que opera en los Ejer- 
cicios Espirituales de San Ignacio se aplica en los ejercicios realizados por José Alejandro Restrepo durante sus puestas en escena. No se indaga aquello que supuestamente inquieta al artista, a saber, las técnicas corporales adecuadas para modelar un determinado tipo de subjetividad. El jurado no explica la relación de la estructura de tales ejercicios con las metodologías de la actuación contemporánea. Tampoco justifica la pertinencia de esta metodología para dramatizar el horror del dolor de los colombianos. La redacción del párrafo mediante el cual se muestra aquello que tenía en mente el jurado en el momento de tomar tan delicada decisión es propia de aquellos que escriben sin haber comprendido, de aquellos que no se han atrevido a preguntar por qué no han comprendido. ¿Qué es aquello que este jurado sabe y el común de la gente ignora? ¿Por qué tienen méritos para ser designados como jurados? Nos quedamos sin saberlo. El portafolio del Idartes no dice nada para persuadir al respecto a la ciudadanía y al campo del arte acerca de la pertinencia de los jurados para cumplir con el propósito encomendado.

La herida en el costado del premio Luis Caballero sigue abierta, el espectáculo y la sombreimposición teórica ahondan sus miserias discursivas. Aunque es justo recordar que estas miserias no son de ahora: los conceptos de otras versiones no son más claros, aunque sí igual de lacónicos y facilistas. Un concepto tan pobre como el formulado para destacar a José Alejandro Restrepo no favorece al artista y deja mal parados a los jurados. Restrepo tiene sus méritos y merece una conceptualización más seria, así sea crítica. Solo la crítica razonada tiene la potencia de enaltecer el gesto artístico, así se equivoque, como en efecto se equivoca muchas veces. Restrepo es un artista joven y sin duda es una promesa del arte nacional. Deja de serlo si se lo entrega a la furia de las lisonjas del mercado.

El jurado no ofrece razones plásticas ni conceptuales al Estado para justificar su decisión. Tampoco este lo requiere, ni pide aclaraciones. El Estado se conforma con un comunicado mal redactado, superficial y desinformado. Parece que no es elegante preguntar por qué se otorgó esta distinción a José Alejandro Restrepo, ni por qué los otros artistas no fueron considerados para tal distinción. Tenemos derecho a saber por qué fueron descalificados y cómo fue el proceso de elección. Como nadie pregunta, nadie responde. Nadie pregunta, porque se sabe que nadie va a responder. Así de contundente es la lógica estética en Colombia.

En otros contextos, el jurado tendría la responsabilidad de explicar a los profanos, en qué consiste la potencia y la aspiración conceptual amplia y universal que le atribuye a Restrepo. El artista merece algo más que esta evasiva formalista. ¿Qué quiere decir que el artista concernido madura investigando lo político? ¿Lo político según San Ignacio? ¿Según la mano visible del mercado que actúa dentro del Estado? ¿Cuál es el santo que orienta la comprensión de lo político en la obra de Restrepo? Ahora bien, ¿qué quieren decir los jurados cuando afirman que la imagen tiene un poder y una responsabilidad dentro del conflicto colombiano? Para saberlo será necesario visitar el Oráculo de Delfos o hacer una peregrinación hasta el Santuario de Nuestra Señora de las Lajas. Dada la complejidad discursiva en que está sumida la producción de arte que reivindica su condición de contemporaneidad, ¿los artistas que andan sumidos en la producción de sus obras son una instancia adecuada para juzgar los méritos de la obra de un artista no correligionario?

El jurado se limita a informar al Estado una obviedad. La propuesta de Restrepo es experimental. Pero, ¿basta con que una obra sea experimental para que merezca una distinción como el premio Luis Caballero? El jurado no se pregunta por la necesidad de esta experimentación: ¿qué tenía que decir el artista que no podía decirlo con una videoinstalación corriente y tuviera necesidad de recurrir al subterfugio sofístico de recurrir a crear falsas expectativas mediante la programación de cuatro sesiones performáticas que rompen con el acuerdo tácito que rige la puesta en gesto del premio Luis Caballero? A este nivel de profesionalización, la experimentación se justifica, si mediante ella se logra cambiar algo en la percepción del espectador. Si no lo hace, la propuesta se hace responsable de prestarse a una espectacularización gratuita del premio. Solo hasta la última sesión, el espectador de Ejercicios Espirituales captó cuál era el sentido o la verdad 
que el artista intentaba modificar, pero también constató que nada en su percepción fue modificado. Más de lo mismo, a tal grado que algo tan grave resulta una obviedad. Con un asunto tan delicado entre manos, el dolor de quienes son agredidos de manera atroz por sus hermanos, no se puede improvisar. La experimentación se justifica si por medio de ella se modifica la manera de percibir la realidad y la manera en que esta produce sus verdades. La propuesta de Restrepo no aporta algo diferente a la comprensión común de que todos tenemos de la guerra atroz que padece este país, tanto por parte de los que están por fuera del Estado, como por parte de aquellos que se lucran por estar dentro de él, marginando a quienes son mejores.

Restrepo solo reitera la manera de juzgar usada por los llamados artistas críticos o políticos. Su puesta en escena final sugiere que los ciudadanos inermes son culpables de los males que padecen los hombres y las mujeres atrapadas por las guerras y el discurso victimizante que los mismos artistas servilmente ilustran. En opinión de los artistas políticos, los ciudadanos no actúan frente a un caso de injusticia. Los artistas críticos o políticos, sacan doble provecho del dolor ajeno. Por una parte, transforman las imágenes de guerra en mercancía suntuaria, y, por otra, avergüenzan a quienes no tienen nada que ver con el conflicto para instalarse como su referente moral. Los responsables materiales e intelectuales de los crímenes atroces que el artista político pretende denunciar, son dejados en un segundo plano. La crítica del artista político está dirigida a los ciudadanos quienes pudiendo actuar no actúan. Esta crítica es razonable pero se desmorona porque el artista mismo no actúa y se limita solo a mercantilizar el dolor y la vergüenza de los demás. Esta variación de la Versión Libre ensayada por Clemencia Echeverry en el V premio Luis Caballero, insiste en juzgar y avergonzar a quién no tiene velas en el entierro. Aunque la variación es la estrategia más adecuada para tener acceso a una esencia, en este caso no se logra variar el estado en el cual Echeverry dejó el asunto tratado.

El Idartes con seguridad tomará cartas en el asunto e implementará para la octava versión del premio, unas estrategias que obliguen a los jurados a tomarse el premio más en serio. Será necesario reformular los criterios actuales de evaluación. En primer lugar, la nominación de artistas debe superar la positividad anglosajona: la solidez formal y conceptual de la propuesta es solo un sofisma distractor implementado para favorecer la arbitrariedad que ejercen tanto los jurados como muchos curadores a nivel nacional. En segundo lugar, es necesario salirse del dispositivo proposicional que impone el criterio de coherencia. Establecerlo como horizonte de producción artística es un exabrupto. Forzar una relación coherente entre la propuesta y el espacio específico, es reducir el gesto artístico a una demostración positivista. La coherencia niega la libertad reivindicada por todo gesto artístico. No puede haber coherencia entre una idea artística y su puesta en obra. He aquí la importancia de la promesa de mil aventuras emancipadoras que nos hace el arte. En tercer lugar, es necesario modificar la medición del aporte de la propuesta al campo artístico. ¿Cuál es el aporte de Ejercicios Espirituales al campo artístico? Nos quedamos sin saberlo. Los jurados designados para hacérnoslo saber se declararon impotentes y, a pesar de ello, todos comieron perdices. No mencionan nada al respecto, por lo tanto es fácil inferir que no cumplieron con su responsabilidad.

Prudente y enigmáticamente, Rodrigo Moura decidió a último momento declinar la invitación a hacer parte del jurado. Este es el lunar más grande en esta versión del premio. Las suspicacias que se expresan en los corrillos artísticos son preocupantes: ¿a último momento se eligió un jurado correligionario de los restantes con el propósito de ratificar una decisión ya tomada? Si es así, ique entre el diablo y escoja!

Fotografías: Jorge Peñuela. Mariana Varela, Fracturas, artista nominada al premio Luis Caballero 2014.

\section{Referencias}

Badiou, Alain [2013]. "Las condiciones del arte contemporáneo". Disponible en http:/ / www. brumaria.net/284-alain-badiou 
[2013]. "El arte contemporá-

neo y la filosofía del dinero". Disponible en http:/ / www.liberatorio.org/index.php?option=com_co ntent\&view=article\&id=357:alain-badioupasion-ficcion-y-dinero\&catid=3:investigaciongeneral\&ltemid $=40$

Agamben, Giorgio [2009]. Desnudez. Buenos Aires: Adriana Hidalgo Editora.

Baumgarten, A.G.; Winckelmann; Mendelssohn. M.; Hamann, J.G. [1999]. Belleza y Verdad. BarceIona: Alba Editorial, S.L.

Deleuze, Guilles [2007]. Pintura. El concepto de diagrama. Buenos Aires: Cactus

Foster, Hal [2001]. El retorno de lo real. Madrid: Akal.

Foucault, Michel [2009]. La hermenéutica del sujeto. México: F.C.E.

los otros. México: F.C.E. [2009b]. El gobierno de sí y de [2009c]. Historia de la Sexualidad, V. 1, La voluntad de Saber. Madrid: Siglo XXI. [2010]. El coraje de la verdad. México: F.C.E.

Idartes. [2012] Cartilla de concursos: http:/ / www.culturarecreacionydeporte.gov.co/portal/ convocatorias/2012/caballero

Peñuela, Jorge [2013]. Post scriptum. José Alejandro Restrepo: el caballero de la fe. Disponible en http:// liberatorio.org/index.php?option $=\mathrm{com}$ content\&view=article\&id=380:post-scriptumjose-alejandro-restrepo-el-caballero-de-la-fepostscriptum-jose-alejandro-restrepo-el-caballero-dela-fe\&catid=10:actualidad-politica\&ltemid =180

[2013]. Séptima versión del premio Luis caballero: apertura a un arte político desideologizado. Disponible en http://liberatorio.org/ index.php?option=com_content\&view=article\&i d=378:septima-version-del-premio-luis-caballeroapertura-a-un-arte-politico-desideologizado\&catid =9:actualidad-estetica\&ltemid $=179$
[2013]. VII Premio Luis Caba-

llero: inauguración en Bogotá de belleza accidental, y otras exposiciones en siete espacios más. Disponible en http:// liberatorio.org/index.php?option=com_ content\&view=article\&id=375:vii-premio-luiscaballero-inauguracion-en-bogota-de-bellezaaccidental-y-otras-exposiciones-en-siete-espaciosmas\&catid=9:actualidad-estetica\&ltemid=179

Rancière, Jacques [2005]. Sobre políticas estéticas. Barcelona: Universitat Autònoma de Barcelona.

[2009]. El reparto de lo sensible. Estética y política. Santiago de Chile: LOM. [2011b]. El malestar en la estética. Buenos Aires. Capital Intelectual S.A. 
